\title{
Correction to: Surgical growth guidance with non-fused anchoring segments in early-onset scoliosis
}

\author{
Dezsö Jeszenszky $^{1} \cdot$ Bettina Kaiser $^{1} \cdot$ Martin Meuli $^{2} \cdot$ Tamas F. Fekete $^{1} \cdot$ Daniel Haschtmann $^{1}$ (I)
}

Published online: 28 August 2019

(c) Springer-Verlag GmbH Germany, part of Springer Nature 2019

\section{Correction to: European Spine Journal (2019) 28:1301-1313 https://doi.org/10.1007/s00586-019-05934-1}

The preoperative X-ray presented in Fig. 1 of the original publication erroneously was not the latest radiographic image taken before the index surgery at the age of 3 years. Instead, it depicts the deformity at the age of 13 months. The X-ray shown below correctly demonstrates the scoliosis 2 months prior to the index surgery and shows the distinctive curve progression. The Cobb angle measurements in Table 2 of the original paper correspond to the X-ray shown below.

The original article can be found online at https://doi.org/10.1007/ s00586-019-05934-1.

Daniel Haschtmann

daniel.haschtmann@kws.ch

1 Department of Spine Surgery and Neurosurgery, Schulthess Klinik, Zurich, Switzerland

2 Department of Paediatric Surgery, University Children's Hospital of Zurich, Zurich, Switzerland

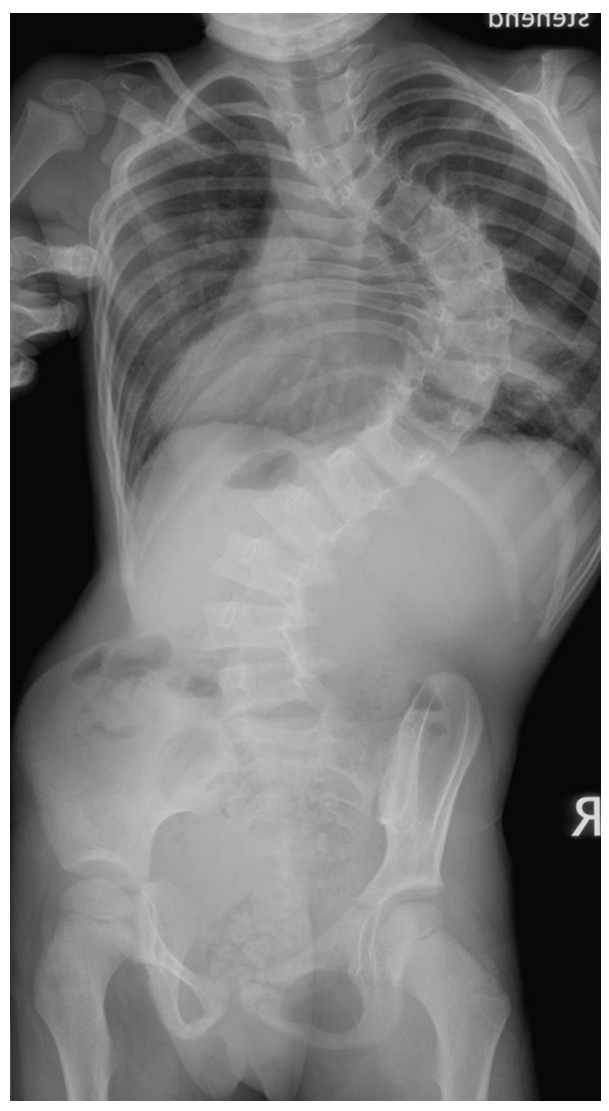

Fig. 1 Pre-index surgery Cobb angle frontal. Preoperative frontal radiograph of the spine. Patient no. 10, 3 years old

Publisher's Note Springer Nature remains neutral with regard to jurisdictional claims in published maps and institutional affiliations. 